\title{
Article
}

\section{Integration of ERT, IP and SP Methods in Hard Rock Engineering}

\author{
Peng Shao ${ }^{1,2,3}$, Yanjun Shang ${ }^{1,2,3, *}$, Muhammad Hasan $1,2,3, * \mathbb{D}$, Xuetao Yi ${ }^{1,2,3}$ and He Meng $1,2,3$ \\ 1 Key Laboratory of Shale Gas and Geoengineering, Institute of Geology and Geophysics, Chinese Academy of \\ Sciences, No. 19, Beitucheng Western Road, Chaoyang District, Beijing 100029, China; \\ shaopeng17@mails.ucas.edu.cn (P.S.); yixuetao19@mails.ucas.ac.cn (X.Y.); menghe20@mails.ucas.ac.cn (H.M.) \\ 2 Innovation Academy for Earth Science, Chinese Academy of Sciences, Beijing 100029, China \\ 3 College of Earth and Planetary Sciences, University of Chinese Academy of Sciences, Beijing 100049, China \\ * Correspondence: jun94@mail.iggcas.ac.cn (Y.S.); hasan.mjiinnww@gmail.com (M.H.); \\ Tel.: +86-139-100-993-15 (Y.S.); +86-130-513-617-10 (M.H.)
}

check for updates

Citation: Shao, P.; Shang, Y.; Hasan, M.; Yi, X.; Meng, H. Integration of ERT, IP and SP Methods in Hard Rock Engineering. Appl. Sci. 2021, 11, 10752. https://doi.org/10.3390/ app112210752

Academic Editors: Arcady Dyskin and Domenico Patella

Received: 15 September 2021

Accepted: 10 November 2021

Published: 15 November 2021

Publisher's Note: MDPI stays neutral with regard to jurisdictional claims in published maps and institutional affiliations.

Copyright: (C) 2021 by the authors. Licensee MDPI, Basel, Switzerland. This article is an open access article distributed under the terms and conditions of the Creative Commons Attribution (CC BY) license (https:/ / creativecommons.org/licenses/by/ $4.0 /)$.
Abstract: Investigation of a hard rock site for the development of engineered structures mainly depends on the delineation of weathered and unweathered rock, and the fractures/faults. Traditionally, borehole tests are used in such investigations. However, such approaches are expensive and time-consuming, require more equipment, cannot be conducted in steep topographic areas, and provide low coverage of the area with point measurements only. Conversely, geophysical methods are non-invasive, economical, and provide large coverage of an area through both vertical and lateral imaging of the subsurface. The geophysical method, electrical resistivity tomography (ERT), can reduce a significant number of expensive drilling tests in geotechnical investigations. However, a geophysical method alone may provide ambiguity in the interpretation of the subsurface, such as electrical resistivity cannot differentiate between water and clay content. Such uncertainty can be improved by the integration of ERT with induced polarization (IP). Similarly, self-potential (SP) can be integrated with other geophysical methods to delineate the groundwater flow. In this contribution, we integrated three geophysical methods (ERT, IP and SP) to delineate the weathered and unweathered rock including the weathered/unweathered transition zone, to detect the fractures/faults, and to map the groundwater flow. Based on ERT, IP and SP results, we develop a geophysical conceptual site model which can be used by site engineers to interpret/implement the findings for build-out. Our approach fills the gaps between the well data and geological model and suggests the most suitable places for the development of engineered structures in the hard rock terrains.

Keywords: electrical resistivity tomography (ERT); induced polarization (IP); self-potential (SP); engineered structures; hard-rock

\section{Introduction}

Given natural heterogeneity, the evaluation of hard rock sites for the construction of engineered structures is a challenging task for planners and engineers. The sustainable design of structures depends on the accurate evaluation of the subsurface geological model [1]. The uncertainty in the subsurface interpretation may cause structure failure [2,3]. A geotechnical site investigation requires time, expenses, and evaluation of subsurface heterogeneity. There is a need to use techniques so that planners can overcome the challenges of a costly and longtime commitment [4]. The construction sites without any proper geotechnical investigation result in building collapse in many developing countries [5]. In the hard rock terrains, the subsurface geological knowledge about the weathered and unweathered rock and the fractures/faults needs to be known for the success of the engineering construction [6]. The weathered zones and fractures/faults are mainly created by tectonic, chemical, erosion and weathering processes. The weathered/fractured zones are mainly associated with groundwater occurrence in the hard rock $[7,8]$. Therefore, identification of the weathered/fractured zones saturated with groundwater is essential to avoid locating engineered structures within potential failure zones [3,6]. 
Traditionally, boreholes are carried out to acquire subsurface geological knowledge $[9,10]$. However, given safety and accessibility issues, it is a challenging task to conduct such tests in steep topographic areas [11,12]. In addition, the drilling approaches are expensive, timeconsuming, need heavy equipment, offer low coverage of point measurements only, and cannot provide lateral information on the subsurface $[13,14]$. Thus, the conventional tests cause uncertainties in the geological model which may lead planners to locate engineered structures at locations where failure is more likely [15]. Therefore, an alternative approach of traditional geotechnical techniques is necessary, which can delineate the subsurface between borehole locations prior to the engineering construction and thus bring a sigh of relief to the engineers.

In the past years, many researchers have used geophysical methods in their investigations [16-28]. Geophysical methods, such as electrical resistivity tomography (ERT), induced polarization (IP) and self-potential (SP) are non-invasive, fast, economical, user friendly, and provide lateral and vertical mapping of the subsurface for large coverage areas $[22,29]$. ERT is widely used in environmental and geotechnical investigations $[3,17,20,23]$. ERT measures electrical resistivity which has a wide range of values and varies with rock type. Unweathered rock has high resistivity, while weathered rock has lower values [10]. Thus, ERT can be used to map the weathered and unweathered zones. However, ERT alone cannot distinguish between water and clay content, since low resistivity suggests water, as well as clay content in the saturated zone [3]. The clay content causes instability in the foundation rock of the engineering structures. Recently, the integration between two or more geophysical methods has been very successful to reduce the uncertainty caused by a single geophysical method $[9,24,25]$. Integration between IP and ERT can remove the uncertainty caused by low values of electrical resistivity as high IP values indicate clay content whereas low IP values reveal water content [30,31]. In addition, ERT coupled with IP can detect the saturated weathered/fractured zones more efficiently since low values of electrical resistivity and chargeability suggest water content [3]. The negative values of SP suggest groundwater flow; thus, SP is very effective to evaluate the groundwater flow mainly along the weathered/fractured zones [10,32].

In this work, we performed an integrated geophysical survey of ERT, IP and SP at a highly heterogeneous hard-rock terrain in order to evaluate the subsurface for site suitability prior to engineering construction. The electrical resistivity obtained by ERT was used to delineate the distinct subsurface layers, such as the topsoil layer, weathered layer, weathered/unweathered transition zone and the unweathered rock at the bottom. Zones of higher clay content were delineated with the integration between ERT and IP. The groundwater flow path was inferred by SP. The 2D models of integrated geophysical methods provide a thorough insight into the subsurface. Compared with conventional geotechnical studies, our contribution reduces the uncertainty caused by the spatially limited data, provides a more accurate geological model via lateral and vertical (2D) imaging of the large area, and suggests the most suitable places for the development of engineering structures in highly heterogeneous hard-rock terrain.

\section{Study Area and Hydrogeology}

The projected area is located in Huangbu, a coastal area of the South China Sea in Guangdong province of China (Figure 1). This investigation is a part of the project conducted by the Institute of Geology and Geophysics, Chinese Academy of Sciences to assess the hard-rock site for the development of engineering structures, such as facilities, laboratories and accelerator-driven systems. The investigated site is located in the Huidong Mountain Ranges including a tributary of Kaozhouyang River in northeast. The simplified geological settings of Huangbu consist of several localized faults, an unconformable boundary between the volcanic acidic rocks of Upper Jurassic and the magmatic/granite rocks of Lower Jurassic, and dynamo metamorphic zones [33]. Tuff rocks are dominant throughout the study area. The project area has a tropical climate system with the monsoon (rainy) season between May and September. The annual mean precipitation is $1950 \mathrm{~mm}$ [33]. 
Huangbu faces natural hazards, such as frequent typhoons, earthquakes and landslides, etc., [10]. It has a long summer with a maximum temperature of $40^{\circ} \mathrm{C}$ and a short winter with a minimum temperature of $5^{\circ} \mathrm{C}$. The geological processes, such as weathering, tectonic and hydrothermal processes mainly cause fracturing in the study area [3]. The excess rainwater enters the fractures/discontinuities and makes the aquifer system. Groundwater resources are found within the weathered rock lying between the topsoil layer and the unweathered rock. Therefore, the delineation of weathered and unweathered rock, clay, and faults is the main challenge prior to the construction of engineered structures.

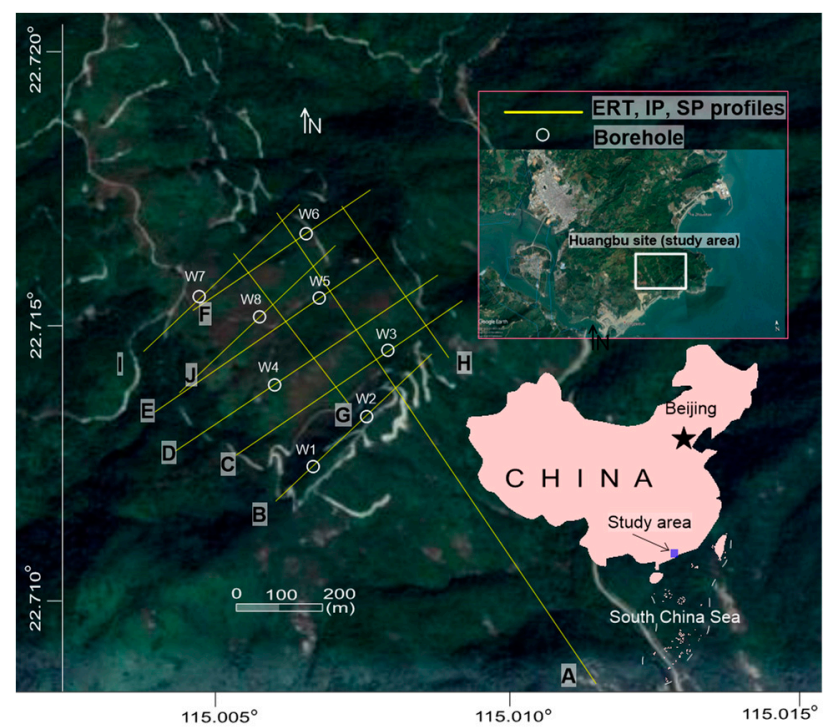

Figure 1. Location of the investigated area including the geophysical profiles (yellow lines) of ERT, IP and SP measurements, and boreholes (white circles).

\section{Materials and Methods}

In the past decades, ERT has been widely used to assess hard-rock sites for the evaluation of weathered and unweathered layers, discontinuities, joints and fractures / faults $[3,7,10,18,19,21,22,34,35]$. It has been highly efficient in the areas dominated by the hydrogeological significance of weathering processes [9,10]. In ERT surveys, electrical resistivity is measured (in $\Omega \mathrm{m}$ ), which depends on the subsurface variations mainly associated with the type of rock, fractures, joints, lithology, water content, porosity, and permeability $[3,36]$. ERT data is collected using different electrode configurations which provide different resolutions [36]. ERT is affected by lithology and electrolytic conduction related to the size and configuration of the pore space, which is dependent on the size and shape of subsurface grains [9]. In general, electrical resistivity decreases with increasing water and clay content [37]. The resistivity of metamorphic and igneous rocks is higher than that of sedimentary rocks; similarly, the resistivity of unweathered rocks is higher than that of weathered/fractured rocks [10]. Thus, a huge contrast between resistivity values of weathered and unweathered rock is useful for the site suitability of the engineered structures [3,9]. ERT surveys are performed by injecting electric current into the subsurface via a pair of current electrodes, and the potential difference is measured through a pair of potential electrodes. The spacing between the electrodes controls the subsurface volume/area of influence. As the electrode spacing increases, the volume/area increases. The electrical resistivity measured in the field is known as the apparent resistivity ( $\rho$ a) and is equal to:

$$
\rho \mathrm{a}=\frac{K V}{I}
$$

where $V$ is the potential difference obtained between two potential electrodes, $I$ is the direct electric current injected through two current electrodes, and $K$ is the geometric factor that depends on the electrode spacings used to collect resistivity measurements. 
The electrical resistivity measured in the field does not show the true resistivity of the subsurface layers $[10,38]$. The apparent resistivity assumes a homogeneous subsurface. To solve for the true resistivity, apparent resistivities must be inverted [3,37].

IP is a method in which the subsurface materials get polarized as a result of the injection of an electric current into the subsurface $[39,40]$. Chargeability (in ms) is measured in the time-domain IP surveys. The electric field causes ions to displace within the EDL (electrical double layer). For time-domain IP, the measurement is the signal decay where displaced ions return back to the original state [41]. IP measurements are affected by the electrolyte properties in pore spaces, size of the grain, type of minerals, surface-water interaction, and the ratio of internal surface area to volume [42]. IP has higher polarization values for clay, sulfides and graphite; whereas its low values suggest the water content associated with the weathered/fractured zones in the hard rock terrains [30,31]. Thus, IP measurements have been very successful to differentiate between clay (with high chargeability and low resistivity) and weathered/fractured rock saturated with water (for low chargeability and low resistivity) [3]. In this investigation, IP was used as a supporting method of ERT to differentiate between water and clay.

$\mathrm{SP}$ is a passive geoelectrical technique, which measures natural potential (in $\mathrm{mV}$ ) between two points on the ground [43]. SP anomalies are sensitive to the streaming potentials (e.g., groundwater flow). The high potential anomalies are mainly caused by conductive minerals, magnetite, sulfide ore bodies, graphite and groundwater flow [44-46]. SP anomalies at this site are mainly controlled by groundwater flow through the weathered/fractured zones [47]. The SP surveys measure positive and negative anomalies depending on the subsurface materials properties $[48,49]$. The groundwater flow system is mainly associated with negative SP anomalies [9]. In order to map the groundwater flow path in the study area, the SP measurements were obtained along with the ERT and IP data

Geophysical data acquisition of ERT, IP and SP was performed along the same profile using the same (constant) electrode spacing and the same number of measurements. All electrodes are connected to the resistivity meter via multi-core cables. The lateral and vertical resolution of the subsurface depends on the spacing between the electrodes. The resolution of a model increases with decreasing electrode spacing; however, this will reduce the depth of investigation. Therefore, electrode spacing should be selected considering a balance between the investigation depth and model resolution. The ERT, IP and SP data were obtained by the ABEM Lund Imaging System (ABEM Terrameter (SAS 4000)) along with ten profiles (A, B, C, D, E, F, G, H, I, and J) (Figure 1). A power amplifier, receiver and transmitter are all integrated into the imaging system. The system, connected with a PC, collects the main survey parameters including injected electric current, voltage, apparent resistivity, chargeability and self-potential. The ERT, IP and SP measurements were obtained using non-polarizing electrodes. Such electrodes are a requirement for IP and SP surveys to reduce contact resistances in electrically resistive mediums. A measurement of apparent resistivity, chargeability, and self-potential is performed for each electrode combination. This reading is displayed on the computer output at the lateral midpoint of the electrode locations and a prescribed depth level. Three parameters (electrical resistivity, chargeability and self-potential) are acquired at each of these points. First, the ERT data were obtained via Imaging System on resistivity mode. Afterwards, IP and SP measurements were obtained by using the Imaging System on IP and SP modes, respectively. The geophysical measurements (ERT, IP and SP) were acquired using the pole-dipole array with $5 \mathrm{~m}$ electrode spacing. The asymmetrical nature of this array was removed via the integration of two independent measurements (forward and reverse). Geophysical data of ERT, IP and SP along ten profiles were acquired for a total of $6150 \mathrm{~m}$ profile length, 1240 electrodes and 31,000 measurements, including 25 layers (depth levels) along each profile with the first layer at $7.5 \mathrm{~m}$ depth and last layer at $127.5 \mathrm{~m}$ depth. Data acquisition parameters of ERT, IP and SP along each profile are given in Table 1. Prior to exporting geoelectrical data (apparent resistivity, chargeability and self-potential) to an inversion package, PROSYSII (IRIS Instruments) was used to display raw data in graphical plots, 
and to separate and remove incorrect data points (low/very high potential readings compared with surrounding readings). Furthermore, the signal strength was also enhanced through the use of stacking, i.e., the repeated measurement of transfer resistance through a number of cycles of current injection. The geophysical data obtained in the field were further processed. The apparent electrical resistivity, IP and assigned data weights were inverted by RES2DINV [37]. ZondSP2D program was used for SP data inversion. In SP inversion, the medium model is created through a number of cells, and each cell has the electrical value and type of conductivity (ion or electronic) properties. RES2DINV provides the $2 \mathrm{D}$ resistivity/IP model via the nonlinear optimization procedure $[37,50]$. The robust constraint was used to enhance the data quality by removing the bad data (data values that cause spikes when compared with the surrounding data points and/or data with standard deviations over the average). Thus, the fit of the data to the model can be improved through filtering or using higher standard deviation weights on bad data. A standard deviation weight measures the dispersion of values when some values have higher weights than others. Data weights determine reciprocal errors which provide a measure of the error caused by an instrument, natural electrical storms and nearby anthropogenic current sources. RES2DINV uses the smoothness-constrained least squares inversion with L2-norm. The inversion program minimized the root mean square error (RMS) up to $5 \%$. RMS is calculated as the square of the difference obtained between the estimated and observed apparent resistivity. The ERT models were generated within three to five iterations. The standard technique of Gauss Newton optimization was used in the inversion program. The inversion method was performed using a low damping factor of 0.03 .

Table 1. Data acquisition parameters of geophysical survey (ERT, IP and SP) including profile name, total number of electrodes for each profile, total profile length, electrode spacing along each profile, depth of first layer, depth of last layer, total layers (depth levels), and total number of measurements.

\begin{tabular}{|c|c|c|c|c|c|c|c|}
\hline Profile & Electrodes & $\begin{array}{l}\text { Profile Length } \\
\text { (m) }\end{array}$ & $\begin{array}{l}\text { Electrode Spacing } \\
\text { (m) }\end{array}$ & $\begin{array}{l}\text { 1st Layer Depth } \\
\text { (m) }\end{array}$ & $\begin{array}{c}\text { Last Layer Dept } \\
(\mathrm{m})\end{array}$ & Layers & Measurements \\
\hline $\mathrm{A}$ & 261 & 1300 & 5 & 7.5 & 127.5 & 25 & 6525 \\
\hline B & 101 & 500 & 5 & 7.5 & 127.5 & 25 & 2525 \\
\hline $\mathrm{C}$ & 111 & 550 & 5 & 7.5 & 127.5 & 25 & 2775 \\
\hline $\mathrm{D}$ & 141 & 700 & 5 & 7.5 & 127.5 & 25 & 3525 \\
\hline $\mathrm{E}$ & 111 & 550 & 5 & 7.5 & 127.5 & 25 & 2775 \\
\hline $\mathrm{F}$ & 121 & 600 & 5 & 7.5 & 127.5 & 25 & 3025 \\
\hline G & 111 & 550 & 5 & 7.5 & 127.5 & 25 & 2775 \\
\hline $\mathrm{H}$ & 81 & 400 & 5 & 7.5 & 127.5 & 25 & 2025 \\
\hline I & 101 & 500 & 5 & 7.5 & 127.5 & 25 & 2525 \\
\hline $\mathrm{J}$ & 101 & 500 & 5 & 7.5 & 127.5 & 25 & 2525 \\
\hline
\end{tabular}

\section{Results and Discussion}

Geophysical data of three methods (ERT, IP and SP) were used to interpret the subsurface for site suitability of engineered structures in the study area. The subsurface was interpreted for the delineation of distinct layers, fractures/faults, clay, and groundwater flow path. 2D ERT models were integrated with the borehole lithological logs to obtain a subsurface model of four distinct layers/zones with specific resistivity values range. Clay was identified by the integration of 2D IP models (with high chargeability) and 2D ERT models (with low resistivity). Groundwater flow was mapped using 2D SP models (with low or negative SP). The main fractures/faults were delineated by the integration of all geophysical models using low values of ERT, IP and SP. One of the interpreted models for three geophysical methods is shown in Figure 2. Based on the correlation between all ERT models and borehole data, the ERT model (Figure 2a) along profile B was interpreted (Figure 2b) for four layers (topsoil cover, weathered layer, weathered/unweathered transition zone (partly weathered rock) and unweathered layer) and four main fractures/faults (F2, F3, F4 and F5). The identified fractures/faults in ERT B also show consistency on IP B (Figure 2c) and SP B model (Figure 2d). The ambiguity in the water-clay distinction caused 
by low resistivity in the ERT model (Figure 2a) was removed by integration of IP (with high chargeability) (Figure 2c). Similarly, negative SP shows the direction of groundwater flow mainly along the identified fractures/faults (Figure 2d). The details of subsurface interpretation for all geophysical profiles are given in the following sections.

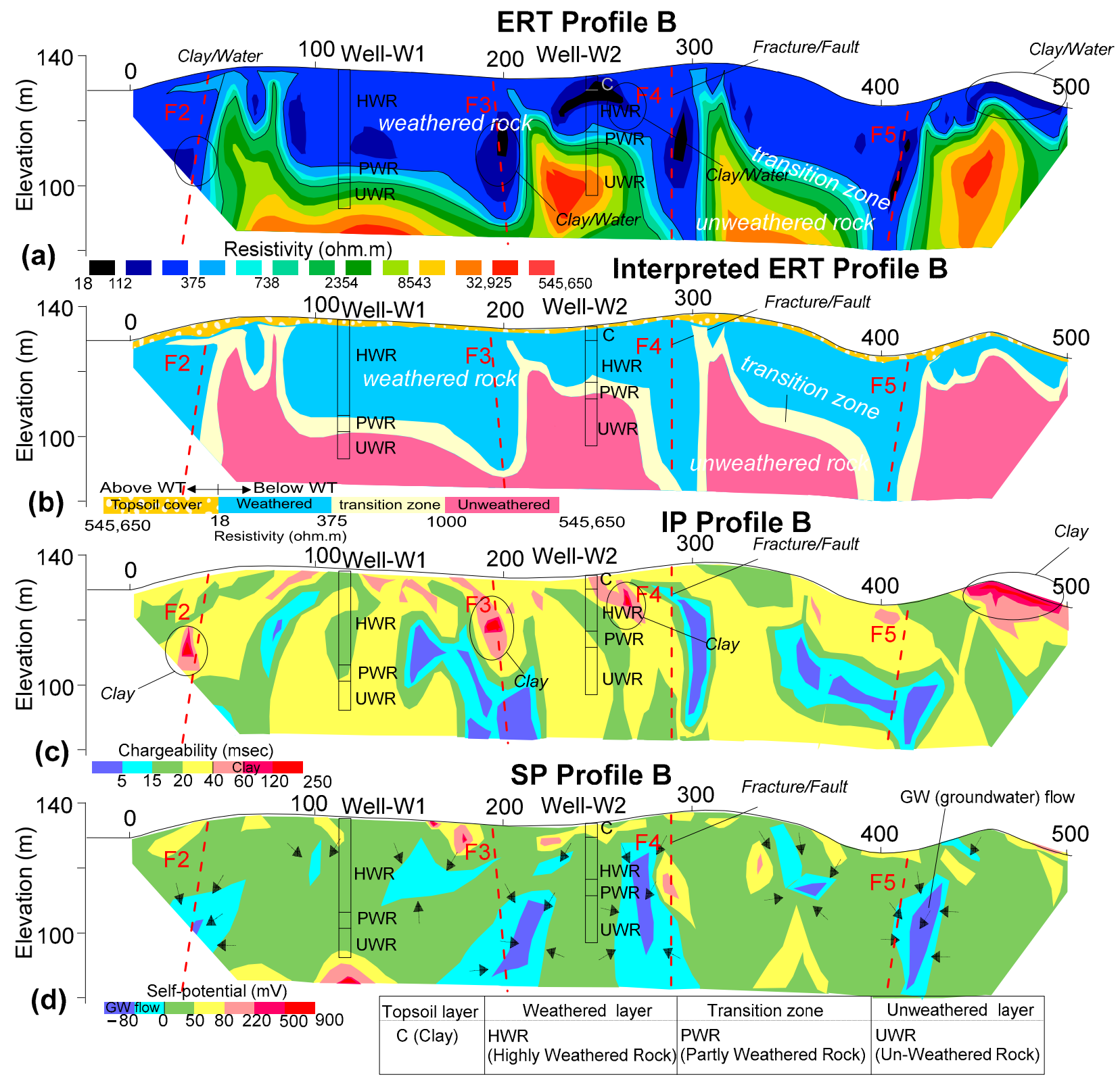

Figure 2. (a) 2D ERT model along profile B, (b) 2D ERT model along the same profile B interpreted for subsurface layers and fractures/faults based on the correlation between ERT models and borehole lithological logs, (c) 2D IP model along the same profile B interpreted for clay and fractures/faults, and (d) 2D SP model along profile B interpreted for groundwater flow path and fractures/faults.

\subsection{Delineation of Subsurface Layers}

The 2D ERT models along with all profiles generated by the inversion program of RES2DINV are shown in Figure 3. The electrical resistivity varies between $18-545,650 \Omega \mathrm{m}$ along all ERT profiles over the entire investigated site. Based on the correlation between ten ERT models and the local hydrogeological information obtained by eight boreholes, the interpretation was constrained for a four-layered model of topsoil cover, weathered layer (highly weathered rock), weathered/unweathered transition zone (partly weathered 
rock) and unweathered layer. The topsoil cover of dry strata above the water table was delineated with a resistivity less than $180,500 \Omega \mathrm{m}$, the weathered layer below the water table underlying the top layer was evaluated with a resistivity between $18-375 \Omega \mathrm{m}$, the unweathered rock at the bottom was revealed with a resistivity greater than $1000 \Omega \mathrm{m}$ and as high as $545,650 \Omega \mathrm{m}$, and the transition zone between weathered and unweathered layer (below the water table) was identified with resistivity ranging from 375 to $1000 \Omega \mathrm{m}$. The weathered layer, unweathered layer and weathered/unweathered transition zone (partly weathered layer) are clearly identified in 2D ERT models shown in Figure 3.

All 2D ERT profiles were integrated and interpreted for the delineation of weathered layer, weathered/unweathered transition zone and unweathered rock as shown in Figure 4. Thus, a 3D view of the integrated 2D ERT profiles provides a clearer view of the subsurface layers over the entire area. Each ERT model in Figures 3 and 4 was interpreted for the identification of the most suitable places for the construction of engineering structures. Average depth/thickness of the delineated topsoil cover, unweathered layer, weathered/unweathered transition zone and weathered layer, including most appropriate locations for engineering construction along each profile are given in Table 2. Results of ten ERT models in Table 2 reveal that the topsoil cover is evaluated with an average depth of $3 \mathrm{~m}$, the weathered layer is evaluated with an average thickness of $14 \mathrm{~m}$, the weathered/unweathered transition zone (partly weathered rock) is interpreted with an average thickness of $8 \mathrm{~m}$, and the unweathered layer is delineated at an average depth of $25 \mathrm{~m}$. The results suggest that ERT profiles $\mathrm{A}, \mathrm{G}$ and $\mathrm{H}$ are more suitable for engineering construction compared with other profiles since they reveal only one deep weathered/transition zone and lower thickness of the weathered rock; while profiles profile B, F, I and J provide the most unsuitable places for construction as they delineate several deep weathered/transition zones and thick weathered layer. Looking at the ERT results alone, the southeastern parts of the project area provide more suitable places for engineering structures due to a shallower depth to the unweathered zone.

Table 2. Results obtained from the interpreted ERT models suggesting the most suitable places for the construction of engineering structures, including average thickness/depth of the topsoil layer, weathered layer, weathered/unweathered transition zone and unweathered layer along each profile.

\begin{tabular}{|c|c|c|c|c|c|}
\hline \multirow{2}{*}{ Profile } & \multicolumn{4}{|c|}{ Average Depth/Thickness of Subsurface Layers } & \multirow{2}{*}{$\begin{array}{l}\text { Most Suitable Places for } \\
\text { Engineering Structures (m) }\end{array}$} \\
\hline & $\begin{array}{c}\text { Topsoil } \\
\text { Thickness (m) }\end{array}$ & $\begin{array}{l}\text { Weathered Layer } \\
\text { Thickness (m) }\end{array}$ & $\begin{array}{l}\text { Transition Zone } \\
\text { Thickness (m) }\end{array}$ & $\begin{array}{c}\text { Unweathered } \\
\text { Layer Depth (m) }\end{array}$ & \\
\hline A & 3 & 10 & 7 & 20 & $60-180,500-800,1000-1300$ \\
\hline B & 3 & 26 & 6 & 35 & $50-75,220-275,430-500$ \\
\hline $\mathrm{C}$ & 3 & 10 & 7 & 20 & $0-175,275-375,425-490$ \\
\hline $\mathrm{D}$ & 3 & 10 & 9 & 22 & $\begin{array}{c}0-100,275-325,375-425 \\
575-700\end{array}$ \\
\hline $\mathrm{E}$ & 2 & 11 & 7 & 20 & $150-275,400-450,480-550$ \\
\hline $\mathrm{F}$ & 3 & 16 & 13 & 32 & $75-225,325-400,500-600$ \\
\hline G & 3 & 11 & 6 & 20 & $240-550$ \\
\hline $\mathrm{H}$ & 2 & 8 & 8 & 18 & $0-250$ \\
\hline I & 5 & 15 & 10 & 30 & $0-50,90-210,325-375,430-450$ \\
\hline $\mathrm{J}$ & 3 & 16 & 11 & 30 & $100-225,290-400$ \\
\hline
\end{tabular}




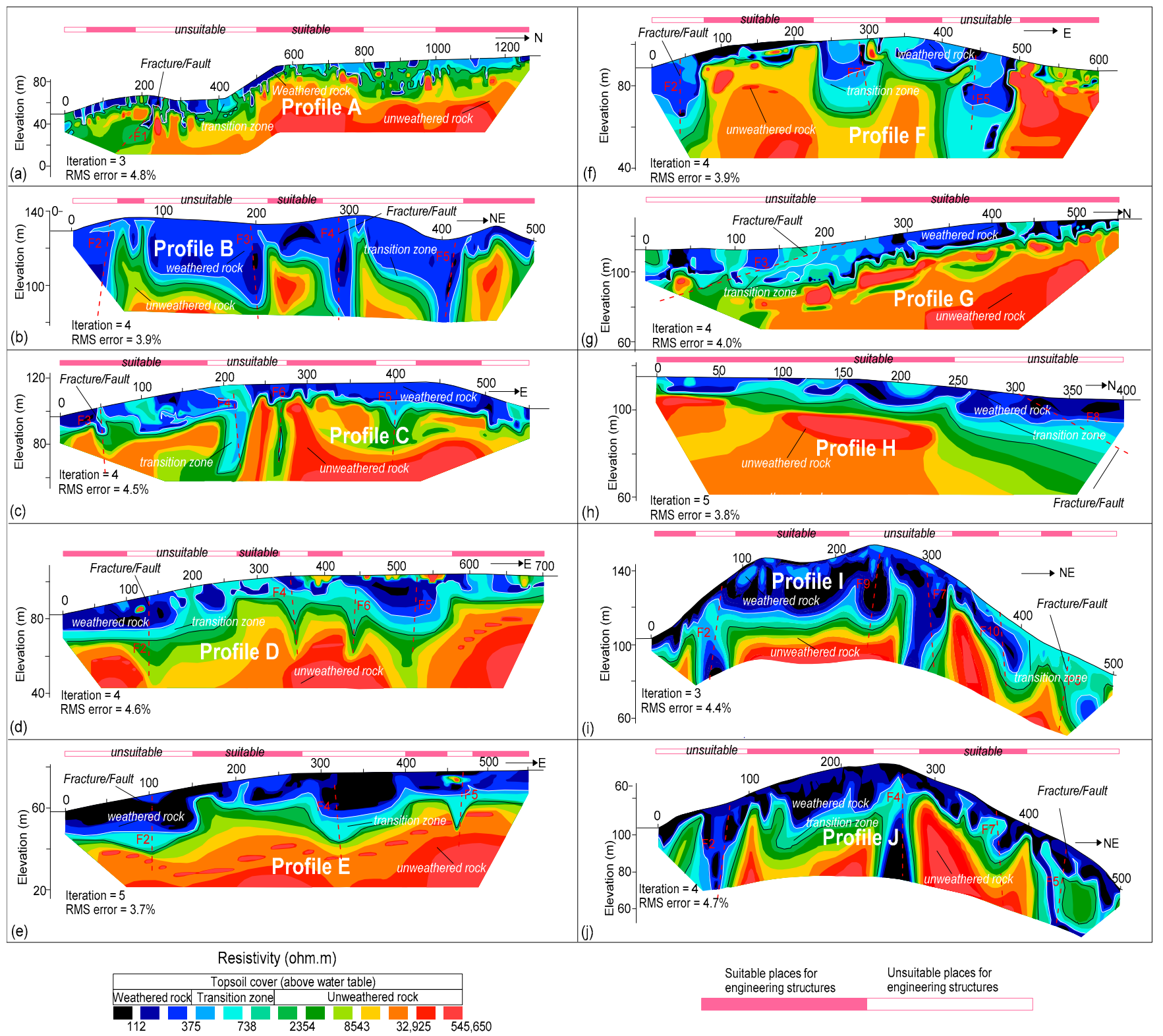

Figure 3. (a-j) 2D resistivity models of ERT (resistivity increasing from black to red on a color scale) along all geophysical profiles generated by the inversion program of RES2DINV. The zones marked by pink color on the top of each ERT model suggest suitable places for engineering structures, whereas the zones of white color indicate unsuitable locations for engineering structures.

\subsection{Detection of Faults}

Low resistive zones (resistivity less than $1000 \Omega \mathrm{m}$ ) were interpreted either as a weathered layer or the fracture/fault. A total of ten main fractures/faults (F1-F10) were delineated over the entire investigated site (Figure 4). These faults were interpreted based on the hydrogeological information of the study area, the deep weathered zones and an overall model generated by the integration of all ERT models (Figure 4). The identified fractures / faults provide the most unsuitable foundation rock for engineering design. Along profile A, one fault (F1) was detected at $220 \mathrm{~m}$ distance. Profile B revealed four faults, such as F2 at 30 m, F3 at 190 m, F4 at $280 \mathrm{~m}$ and F5 at $400 \mathrm{~m}$ distance. Profile C evaluated four faults, such as F3 at $50 \mathrm{~m}, \mathrm{~F} 4$ at $210 \mathrm{~m}, \mathrm{~F} 6$ at $270 \mathrm{~m}$ and F5 at $400 \mathrm{~m}$ distance. Profile D revealed four faults, such as F2 at $130 \mathrm{~m}$ distance, F4 at $350 \mathrm{~m}, \mathrm{~F} 6$ at $450 \mathrm{~m}$, and F5 at $530 \mathrm{~m}$ distance. Profile E detected three faults, such as F2 at 120 m, F4 at 310 m and F5 at 470 m distance. Three faults were identified along profile F, such as F2 at $40 \mathrm{~m}$ distance, F7 at 
$290 \mathrm{~m}$, and F5 at $440 \mathrm{~m}$ distance. Along profile G, one fault (F3) was identified at a distance of $120 \mathrm{~m}$. One fault $\mathrm{F} 8$ was revealed along profile $\mathrm{H}$ in the north at $350 \mathrm{~m}$ distance. Along profile I, five faults were detected, such as F2 at $70 \mathrm{~m}, \mathrm{~F} 9$ at $250 \mathrm{~m}, \mathrm{~F} 7$ at $300 \mathrm{~m}, \mathrm{~F} 10$ at $390 \mathrm{~m}$, and F5 at $470 \mathrm{~m}$ distance. Similarly, four faults were evaluated along profile J, such as F2 at $70 \mathrm{~m}, \mathrm{~F} 4$ at $270 \mathrm{~m}, \mathrm{~F} 7$ at $370 \mathrm{~m}$ and F5 at $450 \mathrm{~m}$ distance. F1 with the northeast-southwest direction was identified along profile $\mathrm{A}$ in the south. The overall orientation of faults F2-F10 is from northwest to southeast. F2 and F5 are the longest faults with about $700 \mathrm{~m}$ in length. F1, F6, F8, F9 and F10 are the shortest faults with lengths of about $150 \mathrm{~m}$. Whereas F3, F4 and F7 are about 300-550 $\mathrm{m}$ long. The fractures/faults were identified by low values of resistivity (Figure 2a), IP (Figure 2c) and SP (Figure 2d).

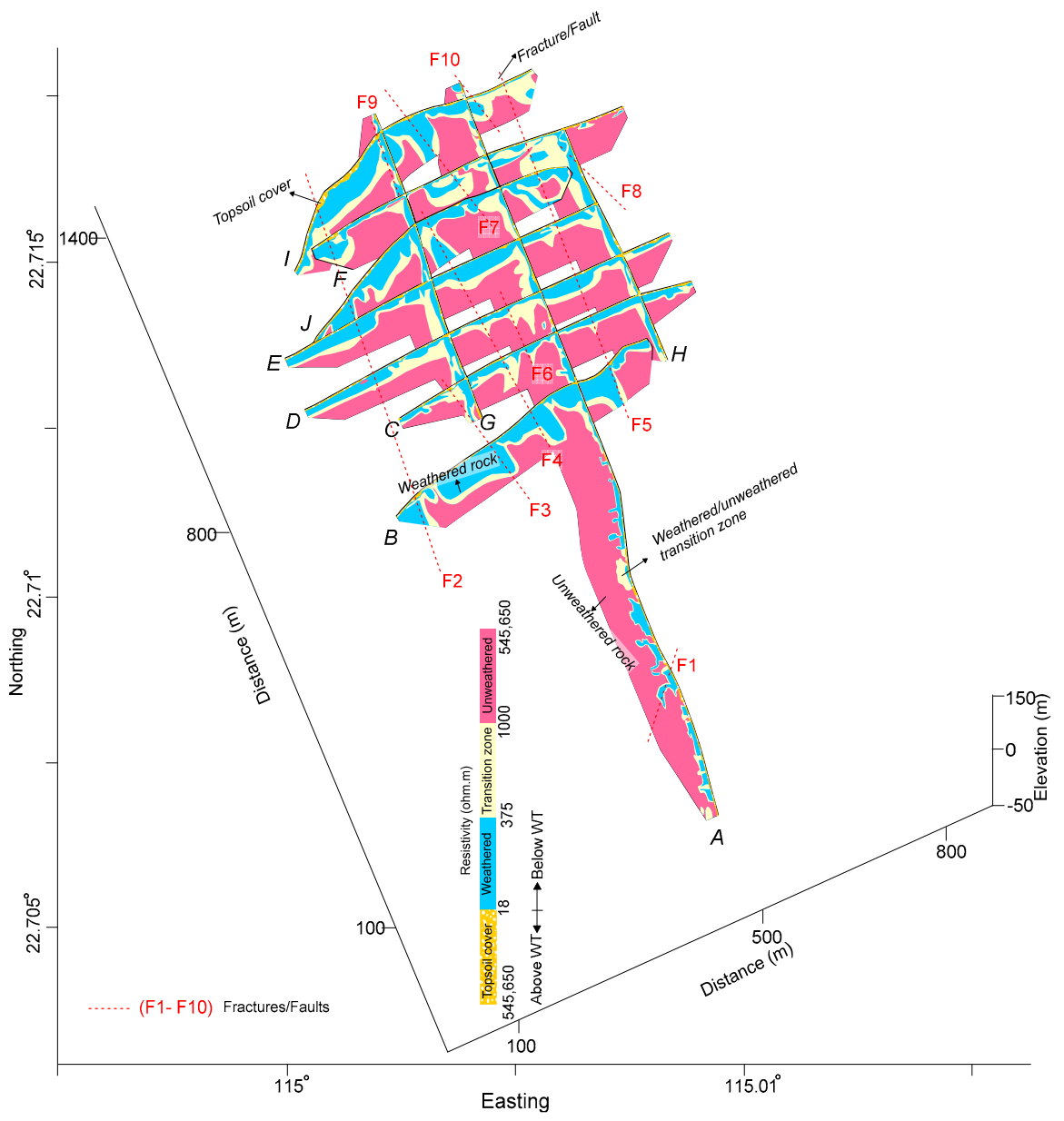

Figure 4. Integration of 2D ERT models along all profiles interpreted for the weathered rock (blue color), weathered/unweathered transition zone or partly weathered rock (yellow color) unweathered rock (pink color), and fractures/faults (dotted reds lines).

\subsection{Water-Clay Distinction}

Electrical resistivity obtained from ERT models cannot distinguish between clay and weathered rock saturated with water, since low resistivity suggests water as well as clay. Thus, ERT models alone cause ambiguity in the interpretation of the subsurface geological model. On the other hand, high IP suggests a higher likelihood of clays while low IP suggests fluid-filled voids. Therefore, such uncertainty in the model was removed by the integration of ERT and IP. Based on the integration between ERT and IP models, and the borehole information, clay was identified with IP greater than $40 \mathrm{~ms}$ and resistivity less than $1000 \Omega \mathrm{m}$. The results suggest that mostly clay was delineated along the fractures/faults near the surface (Figure 5). The prominent clay content along profile A was delineated at $220 \mathrm{~m}, 490 \mathrm{~m}, 1000 \mathrm{~m}$ and $1300 \mathrm{~m}$. Clay was identified at four places along profile B, such as at $30 \mathrm{~m}, 190 \mathrm{~m}, 280 \mathrm{~m}$ and $480 \mathrm{~m}$ distance. Profile $\mathrm{C}$ revealed clay at three locations, such 
as at $40 \mathrm{~m}, 210 \mathrm{~m}$ and $520 \mathrm{~m}$ distance. Profile D revealed thin clay content at several places near the surface. Profile E detected the high clay content at $550 \mathrm{~m}$ on the east side. The main clay content along profile $F$ was revealed at a $500 \mathrm{~m}$ distance. Along profile $\mathrm{G}$, minor clay content was identified at a $75 \mathrm{~m}$ distance. Along profile $\mathrm{H}$, two places of high clay were identified at the integration of profiles $\mathrm{E}$ and F. Along profile I, clay was detected at four places, at $70 \mathrm{~m}, 250 \mathrm{~m}, 300 \mathrm{~m}$ and $390 \mathrm{~m}$ distance. Compared with other profiles, mostly the topsoil layer in profile $\mathrm{J}$ is dominant with clay, especially along the fractures/faults. The locations identified by clay may cause the collapse of the engineered structures. Therefore, clay identified along the 2D IP profiles should be avoided in the construction.

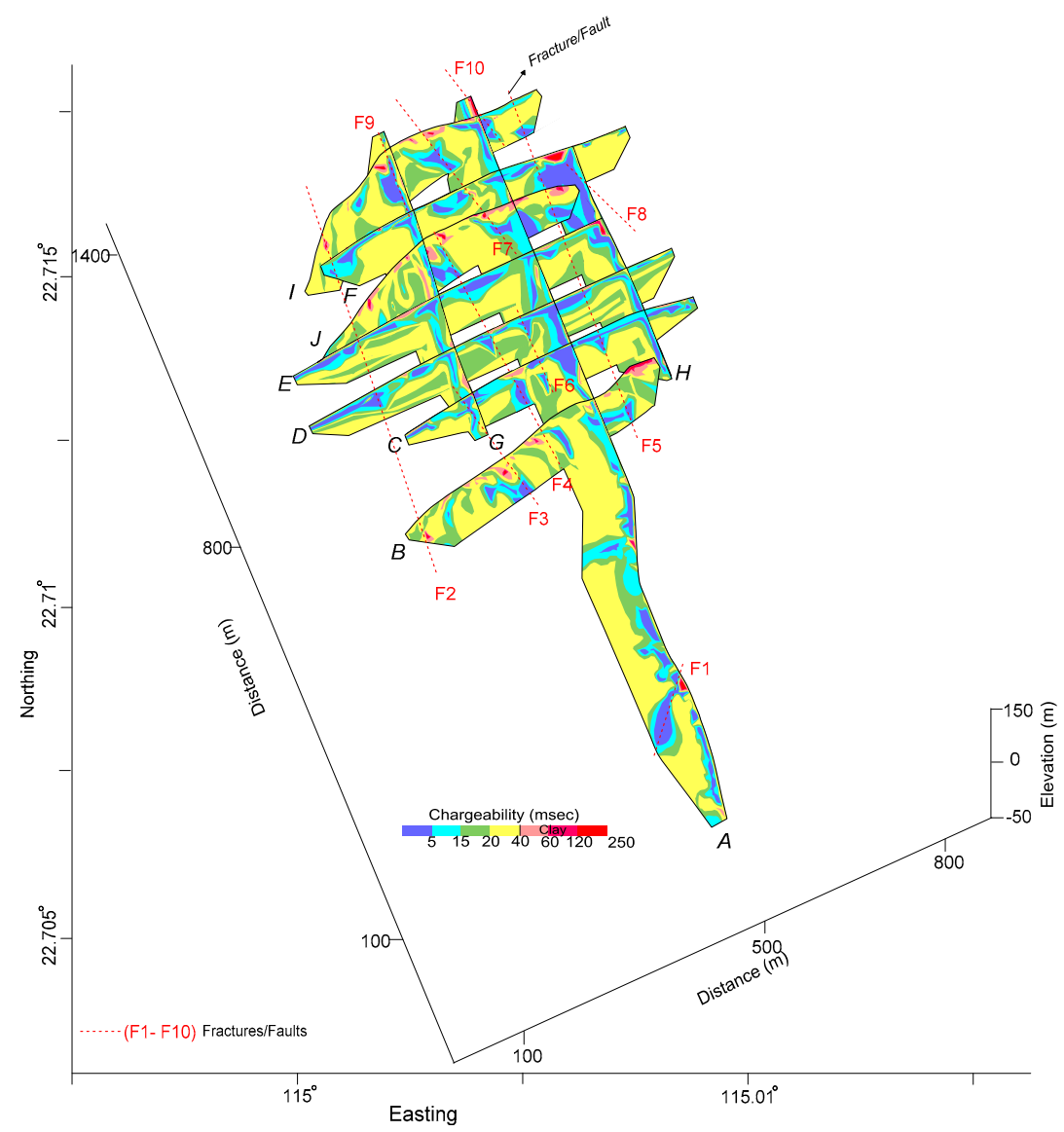

Figure 5. Integration of 10 2D IP models along all profiles (with IP increasing from blue to red on a color bar) interpreted for the clay (shown by red color), and fractures/faults (dotted reds lines).

\subsection{Groundwater Flow Modeling}

Most of the uncertainties in the subsurface geological model were reduced/removed by 2D ERT and IP models through the delineation of weathered and unweathered rock, detection of fractures/faults, and the distinction between water and clay. However, ERT and IP cannot map the groundwater flow in the investigated area. Groundwater flow mapping was performed by SP. SP anomalies suggest both positive and negative values ranging from $-150 \mathrm{mV}$ to $900 \mathrm{mV}$ over the entire investigated area. The negative SP suggests the groundwater flow path. The 2D SP models were generated along the same ERT and IP profiles. The 2D SP models interpreted for the groundwater flow are shown in Figure 6. The integration of 2D SP models provides an overall view of the projected site with clear insights into the subsurface. The SP results suggest that the groundwater flow is mainly mapped along the main fractures/faults. The arrowheads in Figure 6 suggest the groundwater flow direction. Furthermore, the low SP (negative values) delineates the fractures/faults. Hence, in addition to the groundwater flow mapping, SP also supports ERT and IP for the delineation of fractures/faults, and hence the accuracy in the interpretation of 
the subsurface geological model is increased. The results obtained by different geophysical methods show a good correlation with each other and the hydrogeological information of the project site (Figures 2-6). Thus, the use of integrated geophysical methods reduces the geological model uncertainties caused by the limited data and provides more accuracy in the subsurface geological model for the successful construction of engineered structures.

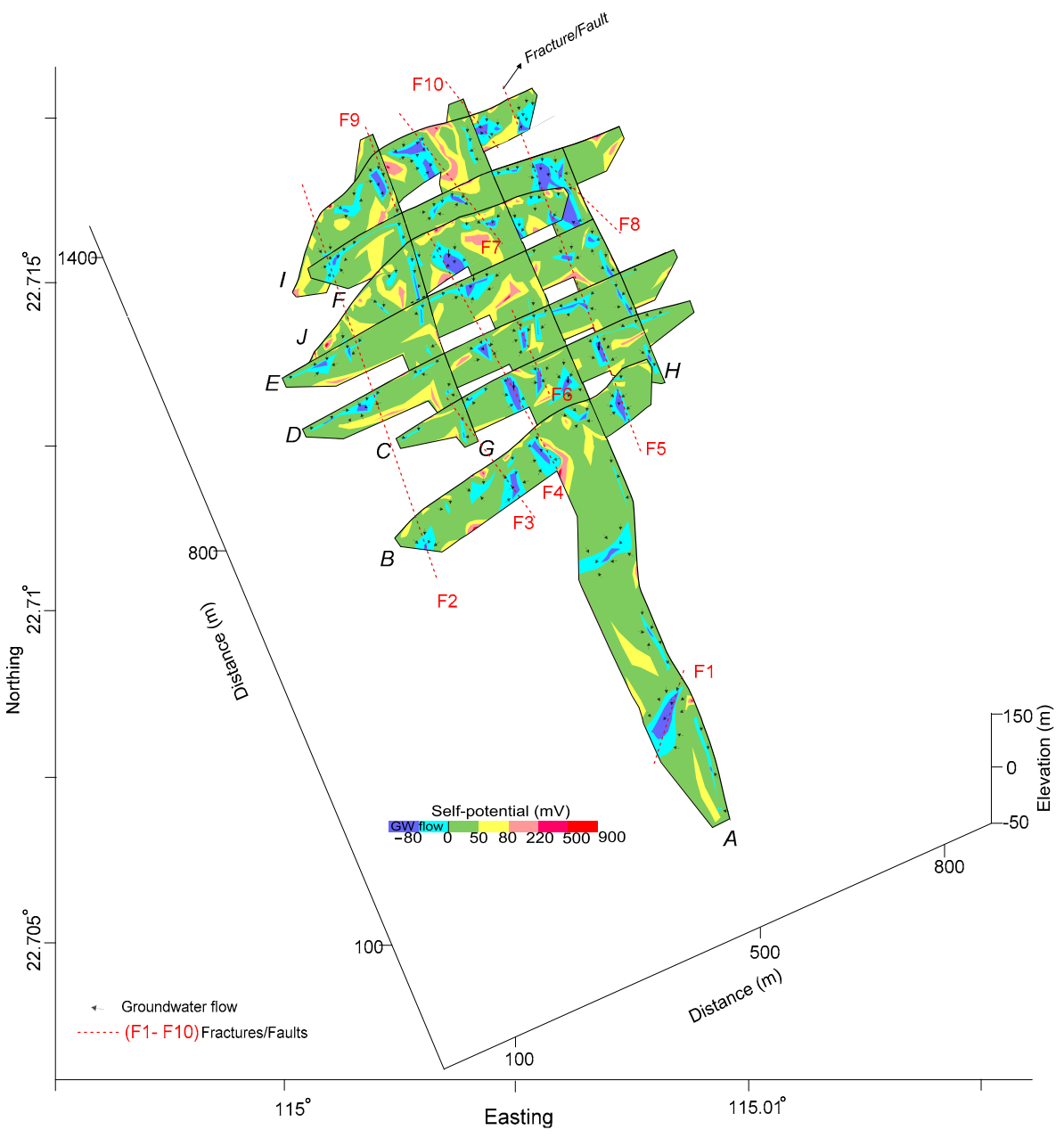

Figure 6. Integration of 2D SP models along all profiles (with SP increasing from blue to red on a color bar) interpreted for the groundwater flow modeling (shown by black arrows) and the fractures/faults (dotted reds lines).

Based on the interpretation of the subsurface using three geophysical methods, a conceptual model of the investigated site was obtained as shown in Figure 7a. The conceptual model provides an overall picture of the study area for the delineation of four distinct layers (topsoil cover, weathered layer, weathered/unweathered transition zone and unweathered layer using ERT, the main faults using ERT, IP and SP, clay using ERT and IP, and groundwater flow path using SP. 


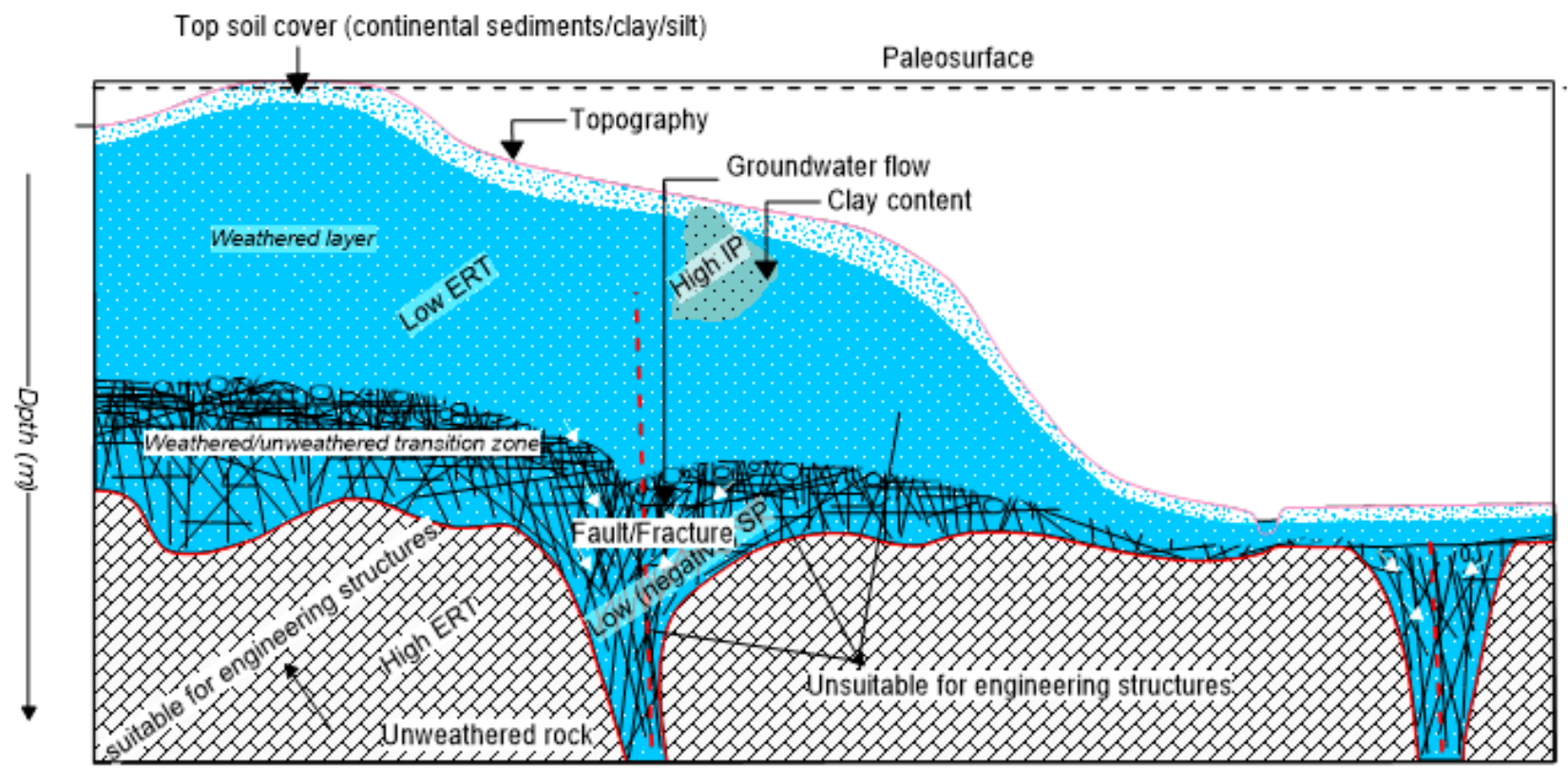

(a)

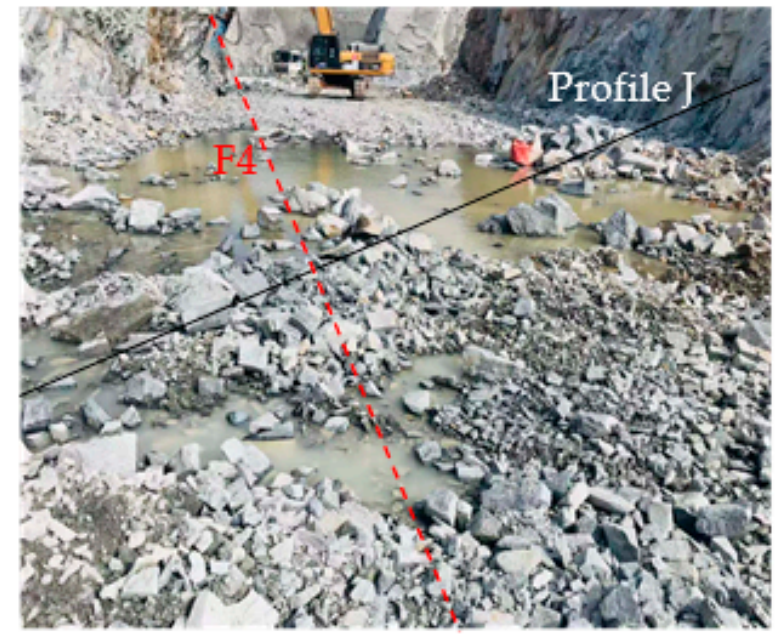

(b)

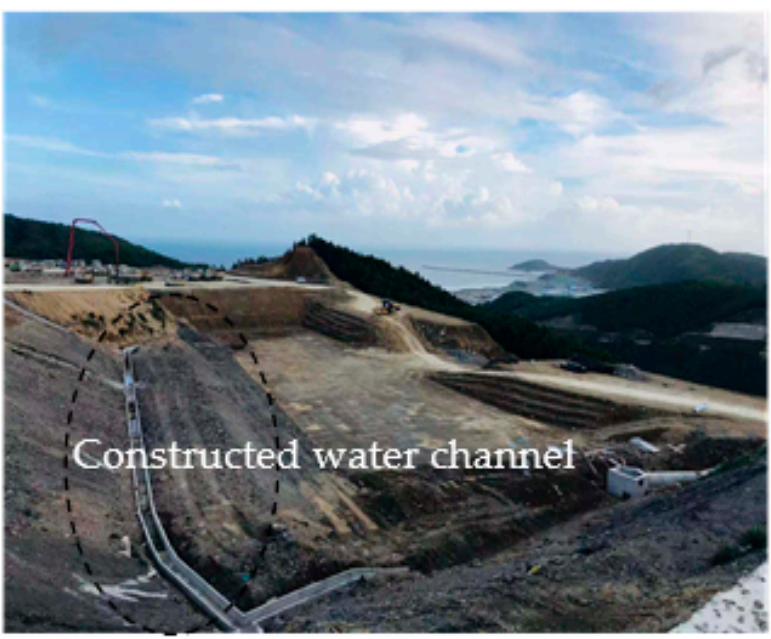

(c)

Figure 7. (a) A four layered-conceptual model of the investigated area obtained using three geophysical methods (ERT, IP and SP) for the delineation of subsurface layers, fractures/faults, clay and groundwater flow, (b) Water seepage during the construction as identified by the interpreted fault F4 along profile J, and (c) A change in construction design was made by constructing a water channel for water infiltration from the identified faults/fractures on southwest side of the project site.

\section{Conclusions}

In this work, we used an integrated approach of three geophysical methods namely electrical resistivity tomography (ERT), induced polarization (IP) and self-potential (SP). We used this geophysical approach to assess a highly heterogeneous site in South China for the successful construction of the engineered structures. Traditionally, drilling tests are conducted to get the subsurface geological information. However, such tests suffer limitations in terms of cost, coverage and topographic constraints, etc. Furthermore, it may not be possible for planners to drill a large number of wells that provide the point measurements vertically. On the other hand, geophysical methods are non-invasive, cheaper, and provide subsurface geological knowledge both laterally and vertically. Such methods can be integrated with the available geological information obtained from the limited boreholes in order to investigate the large area entirely. 
In this work, we calibrated ERT with the local geological information of eight boreholes and constrained the subsurface into four discrete layers with specific values range of resistivities, such as the topsoil layer above water table with a resistivity between $18-180,500 \Omega \mathrm{m}$, the weathered layer with resistivity ranging from 18 and $375 \Omega \mathrm{m}$, the weathered/unweathered transition zone (partly weathered rock) with resistivity ranging from 375 to $1000 \Omega \mathrm{m}$, and the unweathered layer with a resistivity between $18-545,650 \Omega \mathrm{m}$. The interpreted 2D ERT models delineated the subsurface layers over the entire area, such as the topsoil layer with an average thickness of $3 \mathrm{~m}$, the weathered layer with an average thickness of $14 \mathrm{~m}$, transition zone with an average thickness of $8 \mathrm{~m}$, and the unweathered layer at an average depth of $25 \mathrm{~m}$. IP was integrated with ERT to delineate clay since ERT alone cannot differentiate between water and clay because low resistivity shows either clay or water. Clay was identified with chargeability greater than $40 \mathrm{~ms}$ and resistivity less than $1000 \Omega \mathrm{m}$. The deep weathered zones were delineated as the main faults and localized fractures in the project site. Our observation suggests that low values of geophysical parameters (resistivity and chargeability) suggest the faults/fractures saturated with water, such as ERT less than $1000 \Omega \mathrm{m}$, IP less than $15 \mathrm{~ms}$ and SP less than $0 \mathrm{mV}$. Groundwater flow along the faults/fractures was mapped by SP. Negative SP mapped the groundwater accumulation mainly along the faults/fractures. Based on the results of ERT, IP and SP, we recommend the most suitable places for the development of engineering structures along each profile (Table 2). Our findings will help the site engineers with the accurate design of engineering structures in the investigated area. Results of this study including the conceptual model (Figure 7a) will also be useful for the interpretation of nearby sites. Our results were confirmed by the actual situation of the investigated site during the construction, such as groundwater seepage during the site construction was clearly observed from the identified fractures/faults (Figure $7 \mathrm{~b}$ ), and the construction design was modified based on our geophysical results (Figure 7c). Our approach of integrated geophysical methods provides better insights into the subsurface for the construction of engineering structures in highly heterogeneous hard rock terrains.

Author Contributions: Conceptualization, P.S., Y.S. and M.H.; methodology, P.S., Y.S. and M.H.; software, P.S., Y.S., M.H., X.Y. and H.M.; validation, P.S., Y.S. and M.H.; formal analysis, P.S., Y.S. and M.H.; investigation, P.S., Y.S., M.H., X.Y. and H.M.; resources, P.S., Y.S. and M.H.; data curation, P.S., Y.S., M.H., X.Y. and H.M.; writing-original draft preparation, P.S., Y.S., M.H., X.Y. and H.M.; writing —review and editing, P.S., Y.S. and M.H.; visualization, P.S., Y.S., M.H., X.Y. and H.M.; supervision, P.S., Y.S. and M.H.; project administration, P.S., Y.S. and M.H.; funding acquisition, P.S., Y.S. and M.H. All authors have read and agreed to the published version of the manuscript.

Funding: This research was funded by the Chinese Academy of Sciences for a Post-Doctoral fellowship (no. 2020PD01), National Basic Research Program of China (no. 2014CB046901), Chinese National Scientific Foundation Committee (NSFC) (no. 41772320), National Science and Technology Basic Resources Investigation Project (no. 2018FY100503), and the second Tibetan Plateau Scientific Expedition and Research Program (STEP) (no. 2019QZKK0904).

Institutional Review Board Statement: Not applicable.

Informed Consent Statement: Not applicable.

Data Availability Statement: The data used to support the findings of this study are available from the corresponding author upon request.

Acknowledgments: The authors wish to acknowledge the support received from IGG's International Fellowship Initiative (IIFI) for Post-doctorate, and the Key Laboratory of Shale Gas and Geoengineering, Institute of Geology and Geophysics, Chinese Academy of Sciences, Beijing, China.

Conflicts of Interest: The authors declare no conflict of interest.

\section{References}

1. Fan, X.M.; Xu, Q.; Zhang, Z.Y.; Meng, D.S.; Tang, R. The genetic mechanism of a translational landslide. Bull. Eng. Geol. Environ. 2009, 68, 231-244. [CrossRef] 
2. $\quad$ Li, K.; Shang, Y.; He, W.; Lin, D.; Hasan, M.; Wang, K. An engineering site suitability index (ESSI) for the evaluation of geological situations based on a multi-factor interaction matrix. Bull. Eng. Geol. Environ. 2017, 78, 569-577. [CrossRef]

3. Hasan, M.; Shang, Y.; Jin, W.; Akhter, G. An engineering site investigation using non-invasive geophysical approach. Environ. Earth Sci. 2020, 79, 265. [CrossRef]

4. Asch, T.W.J.V.; Hendriks, M.R.; Hessel, R.; Rappange, F.E. Hydrological triggering conditions of landslides in varved clays in the French Alps. Eng. Geol. 1996, 42, 239-251. [CrossRef]

5. Hongbin, L.V.; Chengpeng, L.; Bill, X.H.; Jiaxin, R.; Yanan, Z.; Qiang, X.; Juxiu, T. Characterizing groundwater flow in a translational rock landslide of southwestern China. Bull. Eng. Geol. Environ. 2017, 78, 3223-3237. [CrossRef]

6. Ayodele, Y.G.; Joshua, A.O.; Sunday, O.J. An Engineering Site Characterization using Geophysical Methods: A Case Study from Akure, Southwestern Nigeria. J. Earth Sci. Geotech. Eng. 2015, 5, 57-77.

7. Wyns, R.; Baltassat, J.M.; Lachassagne, P.; Legchenko, A.; Vairon, J.; Mathieu, F. Application of Magnetic Resonance Soundings to Groundwater Reserves Mapping in Weathered Basement Rocks (Brittany, France). Bull. Soc. Géol. Fr. 2002, 175, 21-34. [CrossRef]

8. Taylor, R.; Howard, K. A tectono-geomorphic model of the hydrogeology of deeply weathered crystalline rock: Evidence from Uganda. Hydrogeol. J. 2000, 8, 279-294. [CrossRef]

9. Gao, Q.; Shang, Y.; Hasan, M.; Jin, W.; Yang, P. Evaluation of a Weathered Rock Aquifer Using ERT Method in South Guangdong, China. Water 2018, 10, 293. [CrossRef]

10. Hasan, M.; Shang, Y.; Jin, W. Delineation of weathered/fracture zones for aquifer potential using an integrated geophysical approach: A case study from South China. J. Appl. Geophys. 2018, 157, 47-60. [CrossRef]

11. Guoxing, C.; Jiao, Z.; Mengyun, O.; Wenping, G. Three- dimensional site characterization with borehole data-A case study of Suzhou area. Eng. Geol. 2018, 234, 65-82.

12. Shang, Y.J.; Yang, C.G.; Jin, W.J.; Chen, Y.W.; Hasan, M.; Wang, Y.; Li, K.; Lin, D.M.; Zhou, M. Application of Integrated Geophysical Methods for Site Suitability of Research Infrastructures (RIs) in China. Appl. Sci. 2021, 11, 8666. [CrossRef]

13. Sikandar, P.; Christen, E.W. Geoelectrical sounding for the estimation of hydraulic conductivity of alluvial aquifers. Water Resour. Manag. 2012, 26, 1201-1215. [CrossRef]

14. Chang, L.C.; Ho, C.C.; Yeh, M.S.; Yang, C.C. An integration approach for conjunctive-use planning of surface and subsurface water system. Water Resour. Manag. 2011, 25, 29-78. [CrossRef]

15. Bianchi, G.; Fasani Bozzano, F.; Cardarelli, E.; Cercato, M. Underground cavity investigation within the city of Rome (Italy): A multi-disciplinary approach combining geological and geophysical data. Eng. Geol. 2013, 152, 109-121. [CrossRef]

16. Suzuki, K.; Toda, S.; Kusunoki, K.; Fujimitsu, Y.; Mogi, T.; Jomori, A. Case studies of electrical and electromagnetic methods applied to mapping active faults beneath the thick quaternary. Eng. Geol. 2000, 56, 29-45. [CrossRef]

17. Kneisel, C. Assessment of subsurface lithology in mountain environments using 2D resistivity imaging. Geomorphology 2006, 80, 32-44. [CrossRef]

18. Cardarelli, E.; Cercato, M.; Di Filippo, G. Assessing foundation stability and soil structure interaction through integrated geophysical techniques: A case history in Rome (Italy). Near Surf. Geophys. 2007, 59, 244-259. [CrossRef]

19. Chambers, J.C.; Kuras, O.; Meldrum, P.I.; Ogilvy, R.D.; Hollands, J. Electrical resistivity tomography applied to geologic, hydrologic and engineering investigations at a former waste disposal site. Geophysics 2006, 71, B231-B239. [CrossRef]

20. Martinez, J.; Mendoza, R.; Rey, J.; Sandoval, S.; Hidalgo, M.C. Characterization of Tailings Dams by Electrical Geophysical Methods (ERT, IP): Federico Mine (La Carolina, Southeastern Spain). Minerals 2021, 11, 145. [CrossRef]

21. Kim, J.H.; Yi, M.J.; Song, Y.; Seol, S.J.; Kim, K.S. Application of geophysical methods to the safety analysis of an earth dam. J. Environ. Eng. Geophys. 2007, 12, 221-235. [CrossRef]

22. Osinowo, O.O.; Akanji, A.O.; Akinmosin, A. Integrated geophysical and geotechnical investigation of the failed portion of a road in Basement Complex terrain, southwestern Nigeria. RMZ-Mater. Geoenviron. 2011, 58, 143-162.

23. Lghoul, M.; Teixido, T.; Pena, J.A.; Hakkou, R.; Kchikach, A.; Guerin, R.; Jaffal, M.; Zouhri, L. Electrical and Seismic Tomography Used to Image the Structure of a Tailings Pond at the Abandoned Kettara Mine, Morocco. Int. J. Mine Water 2012, 31, 53-61.

24. Loperte, A.; Soldovieri, F.; Palombo, A.; Santini, F.; Llapenna, V. An integrated geophysical approach for water infiltration detection and characterization at Monte Cotugno rock-fill Dam (southern Italy). Eng. Geol. 2016, 211, 162-170. [CrossRef]

25. Samyn, K.; Mathieu, F.; Bitri, A.; Nachbaur, A.; Closset, L. Integrated geophysical approach in assessing karst presence and sinkhole susceptibility along flood-protection dykes of the Loire River, Orléans, France. Eng. Geol. 2014, 183, 170-184. [CrossRef]

26. Lin, C.H.; Lin, C.P.; Hung, Y.C.; Chung, C.C.; Wu, P.L.; Liu, H.C. Application of geophysical methods in a dam project: Life cycle perspective and Taiwan experience. J. Appl. Geophys. 2018, 158, 82-92. [CrossRef]

27. Kukemilks, K.; Wagner, J.F. Detection of Preferential Water Flow by Electrical Resistivity Tomography and Self-Potential Method. Appl. Sci. 2021, 11, 4224. [CrossRef]

28. Hung, Y.C.; Chou, H.S.; Lin, C.P. Appraisal of the Spatial Resolution of 2D Electrical Resistivity Tomography for Geotechnical Investigation. Appl. Sci. 2020, 10, 4394. [CrossRef]

29. Hasan, M.; Shang, Y.; Jin, W.; Akhter, G. Investigation of fractured rock aquifer in South China using electrical resistivity tomography and self-potential methods. J. Mt. Sci. 2019, 16, 850-869. [CrossRef]

30. Revil, A.; Murugesu, M.; Prasad, M.; Le Breton, M. Alteration of volcanic rocks: A new non-intrusive indicator based on induced polarization measurements. J. Volcanol. Geotherm. Res. 2017, 341, 351-362. [CrossRef] 
31. Johnson, T.C.; Versteeg, R.J.; Ward, A.F.; Day-Lewis, D.; Revil, A. Improved hydrogeophysical characterization and monitoring through high performance electrical geophysical modeling and inversion. Geophysics 2010, 75, WA27-WA41. [CrossRef]

32. Jardani, A.; Revil, A.; Barrash, W.; Crespy, A.; Rizzo, E.; Straface, S.; Cardiff, M.; Malama, B.; Miller, C.; Johnson, T. Reconstruction of the water table from self potential data: A Bayesian approach. Groundwater 2009, 47, 213-227. [CrossRef]

33. Bureau of Geology and Mineral Resources of Guangdong Province. Regional Geology of Guangdong Province; Geology Publishing House: Beijing, China, 1988; pp. 1-602. (In Chinese)

34. Tejero, A.; Chávez, R.E.; Urbierta, J.; Flores-Márquez, E.L. Cavity detection in the southwestern hilly portion of Mexico City by resistivity imaging. J. Environ. Eng. Geophys. 2002, 7, 130-139. [CrossRef]

35. Lech, M.; Skutnik, Z.; Bajda, M.; Markowska-Lech, K. Applications of Electrical Resistivity Surveys in Solving Selected Geotechnical and Environmental Problems. Appl. Sci. 2020, 10, 2263. [CrossRef]

36. Loke, M.H.; Acworth, I.; Dahlin, T. A comparison of smooth and blocky inversion methods in 2D electrical imaging surveys. Explor. Geophys. 2003, 34, 182-187. [CrossRef]

37. Loke, M.H.; Barker, R.D. Rapid least-squares inversion of apparent resistivity pseudosections by a quasi-Newton method. Geophys. Prospect. 1996, 44, 131-152. [CrossRef]

38. Loke, M.H.; Chambers, J.E.; Rucker, D.F.; Kuras, O.; Wilkinson, P.B. Recent developments in the direct-current geoelectrical imaging method. J. Appl. Geophys. 2013, 95, 135-156. [CrossRef]

39. Ward, S.H. Resistivity and Induced Polarization Methods in Geotechnical and Environmental Geophysics; Society of Exploration Geophysicists: Tulsa, OK, USA, 1990; pp. 147-190.

40. Routh, P.S.; Oldenburg, D.W. Electromagnetic coupling in frequency-domain induced polarization: A method for removal. Geophys. J. Int. 2001, 145, 59-76. [CrossRef]

41. Dahlin, T.; Leroux, V.; Nissen, J. Measuring Techniques in Induced Polarization Imaging. J. Appl. Geophys. 2002, 50, 279-298. [CrossRef]

42. Yuval; Oldenburg, D.W. Computation of Cole-Cole parameters from IP data. Geophysics 1997, 62, 436-448. [CrossRef]

43. Telford, W.M.; Geldarl, L.P.; Sheriff, R.E. Applied Geophysics; Cambridge University Press: Cambridge, UK, 1990.

44. Meisner, P. A method of qualitative interpretation of self potential measurements. Geophys. Prospect. 1962, 10, 203-218. [CrossRef]

45. Paul, M.K. Direct interpretation of self-potential anomalies caused by inclined sheets of finite horizontal extension. Geophysics 1965, 30, 418-423. [CrossRef]

46. Lowrie, W. Fundamentals of Geophysics; Cambridge University Press: Cambridge, UK, 1997.

47. Self Potential Technique. 2008. Available online: http:/ / www.nga.com/Geo_ser_Self_potential_tech.htm (accessed on 20 July 2008).

48. Mitchell, J.K. Fundamentals of Soil Behavior; John Wiley and Sons: New York, NY, USA, 1976.

49. Corwin, R.F.; Hoover, D.B. The self potential method in geothermal exploration. Geophysics 1979, 44, 226. [CrossRef]

50. Griffiths, D.H.; Barker, R.D. Two-dimensional resistivity imaging and modeling in areas of complex geology. J. Appl. Geophys. 1993, 29, 211-226. [CrossRef] 